\title{
Fatal formalin poisoning: A rare case report
}

\author{
Raut S. M. ${ }^{1}$, Haridas S.V., ${ }^{2,}$ Kachare R.V. ${ }^{3}$, Pawar V.G. ${ }^{4}$, Dode P. S. ${ }^{5}$ \\ ${ }^{1}$ Junior Resident, ${ }^{2}$ Assistant Professor, ${ }^{3}$ Professor \& Head, ${ }^{4}$ Associate Professor, ${ }^{5}$ Assistant Professor, Dept. of \\ Forensic Medicine, Swami Ramanand, Teerth Rural Government Medical College and Hospital, Ambajogai Dist. \\ Beed, Maharashtra, India \\ *Corresponding Author: \\ Email: sandeepvharidas@gmail.com
}

\begin{abstract}
Formaldehyde is a colourless gas with strong pungent smell. Formalin is an aqueous solution of formaldehyde containing $37-40 \%$ formaldehyde and 10-15\% methanol. Commercially available formalin is a 1:10 dilution containing 3.7\% of formaldehyde. Suicidal ingestion of formalin is rare as it has strong taste and suffocating odour, also the common people does not have an easy access to it. That is why suicidal cases by formalin consumption are rare. We herewith present a case report of a 45-year old farmer who committed suicide by formalin consumption.
\end{abstract}

Keywords: Formalin, Suicide, Farmer.

\section{Introduction}

Formalin is a protoplasmic poison and causes coagulation necrosis, protein precipitation, and tissue fixation. ${ }^{1}$ It is a commonly available substance which is used as a disinfectant. The use of formalin in medical practice is mainly confined to preservation of biopsy samples or tissues and also as an embalming fluid as it acts as a tissue fixative. It is irritating, corrosive, toxic and absorbed from all the surfaces of the body. The potentially highly exposed population includes pathologists, funeral service workers, medical, dental and nursing students. ${ }^{2}$ Formaldehyde is also used as an ingredient in fertilizers, biocides, antimicrobial, hair shampoos and conditioners, industrial and soil sterilants etc. Formaldehyde reacts rapidly with DNA, RNA, and proteins in biologic systems. When cells are exposed to high concentrations, cellular functions cease and necrosis is rapid. Formaldehyde may affect neural functions by condensing nonenzymatically with neuroamines, catecholamines and indolamines to form tetrahydroisoquinolines and tetrahydrobetacarbolines respectively. ${ }^{3}$ Accidental exposure to formalin is common as an occupational hazard. Suicidal cases are uncommon as the general population does not have an easy access to it, and it is more often seen in people working in the health industry. ${ }^{4}$ Also, Formalin is an unusual poison to be ingested in suicidal attempts due to selective availability and its strong taste and odour. Hence it is unusual for a farmer to consume formalin for suicidal purpose. Here a case of farmer who committed suicide by formalin consumption.

\section{Case Report}

As per police inquest and report, A 45 year old male had alleged history of consumption of poison on 03.06.2018 at 23.30hrs due to Debt from bank due to drought for consecutive 3 years. He was then brought to casualty of our hospital for treatment where he was declared as brought dead. Body was then transferred to mortuary for Medico-legal post mortem examination.

On external examination, deceased was averagely built, body was cold on touch. Body was cold. There was cold stiffening and post mortem lividity was present over back except pressure areas and bony prominences, fixed and purple. There were no external injuries over body.

On internal examination, esophageal wall was firm and thickening present at distal end. Mucosa was brownish in color. Stomach contained $50 \mathrm{ml}$ clear fluid. Smell of formalin was perceived. Mucosa was brownish. Wall of the stomach was firm and thickening present. Rests of the organs were within normal limits.

We preserved the routine viscera for chemical analysis and tissues were preserved for Histopathological examination.

Chemical analysis report from the regional forensic science laboratory confirmed the presence of formaldehyde compound. Histopathological examination of part of stomach revealed "Degenerated and ulcerated mucosal epithelium, underneath all layers show chronic inflammatory infiltrate with congested blood vessels at places. Rest of the tissues were unremarkable".

Final cause of death was ascertained as "Death due to formalin poisoning."

\section{Discussion}

Exposure to formaldehyde mainly occurs via the route of inhalation and ingestion. Inhalation presents with asthma like symptoms like coughing, lacrimation, dyspnea, chest pain and wheezing. On the other hand Ingestion may show features of severe abdominal pain, vomiting, diarrhea, tachypnea, and hypotension. ${ }^{1}$ When ingested, it may produce extensive change in GIT and sufficient formaldehyde may be absorbed and metabolized rapidly to form Formic acid. ${ }^{2,5}$ Formic 
acid, in turn, accumulates rapidly in the blood leading to metabolic acidosis. Formalin may also cause myocardial toxicity ${ }^{6}$ and has a direct oxidant action on red blood cells leading to acute intravascular haemolysis. $^{7}$ Ingestion of formalin may produce corrosive damage of the stomach and intestines. ${ }^{6}$ It can also produce toxic pulmonary oedema, leather like thickening of the gastric wall and multiple subendocardial haemorrhages. ${ }^{8}$ As formalin comes in contact with the gastric mucosa longer than other parts of the gastrointestinal tract, the ingestion of formalin can lead to chemical peritonitis even without perforation. ${ }^{9}$ At autopsy, the smell of formalin might be noticed upon opening the body. Odor of formalin may be present in the stomach. The mucous membrane of the stomach may be red, inflamed and eroded with the extravasation of blood, or may be leathery, fixed, and hard to touch. The duodenum may present the same appearance as that of the stomach and histological details may be well preserved. Kidneys may reveal microscopic evidence of tubular necrosis. ${ }^{10}$ Due to its fixative property it can precipitate proteins. The "fixing" of the stomach by formaldehyde may produce delayed absorption following formalin ingestion. ${ }^{11}$ Formaldehyde is a corrosive material that can produce late sequelae similar to the more common ingestion of acids and alkali. ${ }^{12}$ Most of the formalin poisonings reported were suicidal in nature. However, accidental cases have also been reported. ${ }^{13}$

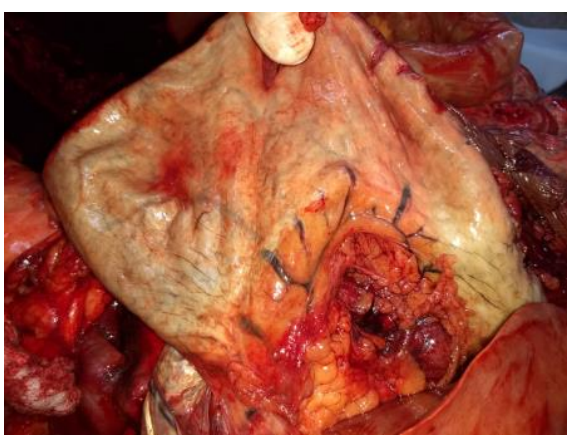

Fig. 1 External appearance of stomach with congested vessels

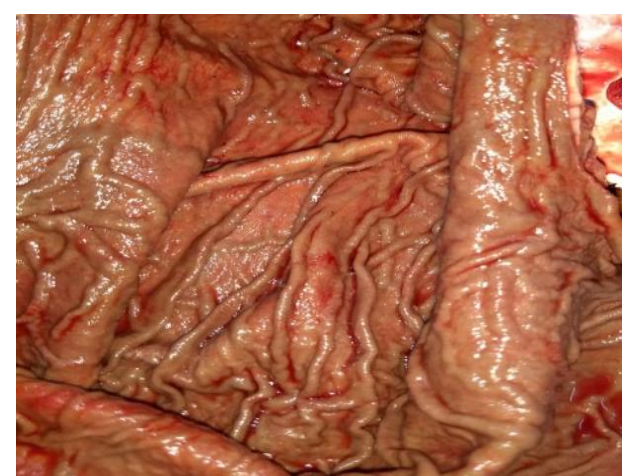

Fig. 2 Stomach mucosa thickening with brownish discoloration

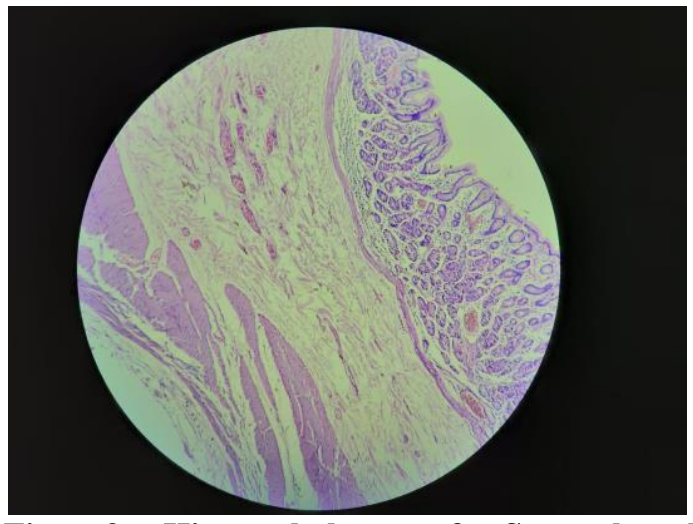

Fig. 3 Histopathology of Stomach showed degenerated and ulcerated epithelium with inflammatory infiltrate and congested blood vessels

\section{Conclusion}

Formalin is an unusual poison to be ingested in suicidal attempts due to selective availability and its strong taste and odour. Cases of mortality due to formalin ingestion are reported comparatively rare in literature. This case shows that the forensic expert should be alert in such cases and the proper autopsy protocol should be followed. Meticulous dissection and the proper preservation of the viscera for chemical analysis and histopathology are indicated in such cases, which help in identifying the cause of death.

\section{Conflict Interest: Nill}

\section{References}

1. Pillay V. V. Modern Medical Toxicology. 4th ed. New Delhi: Jaypee Brothers Medical Publishers; 2013. 352-54.

2. Vicallio P. Industrial and household toxicology, Ch. Toxicity of household products, Emergeny Toxicology. 2nd ed. Philadelphia-New York: Lippincott-Raven Publishers; 1998;520-21.

3. Ellenhorn M, Schonwald S, Ordog G, Wasserberger J. Ellenhorn's Medical Toxicology: Diagnosis and Treatment of Human Poisoning. 2nd ed. Williams \& Wilkins; 1997;1214-1217.

4. Hungund C, Mohanram A, Pai V, Rani S. Fatal Formalin Poisoning: A Case Report. Iranian Journal of Toxicology. 2011;5(1,2):468-69.

5. Ford MD, Delaney KA, Ling LJ, Erikson T. Antiseptics, disinfectants, and sterilizing agents, Clinical Toxicology. New York: W.B Saunders company Philadelphia. 2001;751-752

6. Koppel C, Baudisch H, Schneider V, Ibe K. Suicidal ingestion of formalin with fatal complications. Intensive Care Med. 1990;16(3):212-14.

7. Pun KK, Young CK, Chan TK. Acute intravascular haemolysis due to accidental formalin intoxication during haemodialysis. Clinical Nephrology. 1984;21:188-90.

8. Burkhart KK, Kulig WW, McMartin KE. Formate levels following a formalin ingestion. Vet Hum Toxicol. 990;32:135-37.

9. Yanagawa Y, Kaneko N, Hatanaka K, Sakamoto T, Okada Y, Yoshimitu S. A case of attempted suicide from the ingestion of formalin. Clin Toxical. 2007;45(1):7276.

10. Mathiharan K, Patnaik AK. Modi's Medical 
jurisprudence and Toxicology. 23rd ed. New Delhi; 2002.

11. Sperhake J, Tsokos M, Sperhake K. Perimortem fixation of the gastric and duodenal mucosa: a diagnostic indication for oral poisoning. Int J Legal Med. 1999;112(5):317-20.

12. Hawley CK, Harsch HH. Gastric outlet obstruction as a late complication of formaldehyde ingestion: a case report. Am J Gastroenterol. 1999;94(8):2289-91.

13. Lian CB, Ngeow WC. The adverse effect of formalin - a warning against mishandling. Annal Dent Univ Mallaya. 2000;7:56-58. 